\title{
El listado de verificación como herramienta para la realización de informes periciales a particulares en las reclamaciones por hechos relativos a los accidentes de tráfico.
}

Santiago Sáez, Andrés, García Martín, Ángel, Dorado Fernández, Enrique, Labajo González, Elena, Albarrán Juan, María Elena y Perea Pérez, Bernardo.

Cita:

Santiago Sáez, Andrés, García Martín, Ángel, Dorado Fernández, Enrique, Labajo González, Elena, Albarrán Juan, María Elena y Perea Pérez, Bernardo (2017). El listado de verificación como herramienta para la realización de informes periciales a particulares en las reclamaciones por hechos relativos a los accidentes de tráfico. Revista Española de Medicina Legal, 23 (3), 127-130.

Dirección estable: https://www.aacademica.org/elenalabajogonzalez/35 ARK: https://n2t.net/ark:/13683/pcQr/usy

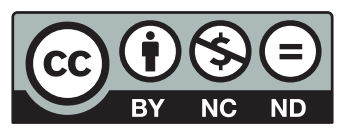




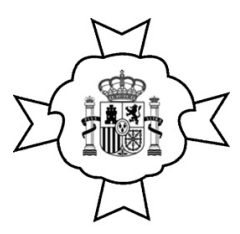

ASOCIACIÓN NACIONAL MÉDICOS FORENSES
REVISTA ESPAÑOLA DE

MEDICINA LEGAL

www.elsevier.es/mlegal

\title{
El listado de verificación como herramienta para la realización de informes periciales a particulares en las reclamaciones por hechos relativos a los accidentes de tráfico
}

\section{The checklist as a tool for drawing up expert reports issued to individuals concerning road traffic accident claims}

\author{
Andrés S. Santiago-Sáez*, Ángel F. García-Martín, Enrique Dorado-Fernández, \\ Elena Labajo-González, María Elena Albarrán-Juan y Bernardo Perea-Pérez
}

Departamento de Toxicología y Legislación Sanitaria, Facultad de Medicina, Universidad Complutense de Madrid (UCM), Madrid, España

\section{Introducción}

El baremo de indemnizaciones por accidentes de tráfico es un conjunto estructurado de normas establecidas convencionalmente en la ley para poder evaluar, determinar y calcular la cuantía de las indemnizaciones que le corresponden a una persona que haya sufrido un accidente de tráfico ${ }^{1}$.

El 1 de enero de 2016 entró en vigor en la legislación española, a través de la Ley 35/2015, de 22 de septiembre, un nuevo sistema reformado para la valoración de los daños y perjuicios causados a las personas en accidentes de circulación ${ }^{2}$. Esta ley ha supuesto un cambio muy importante para poder adaptarse a la situación actual de siniestralidad en España.

La importancia de este baremo trasciende el ámbito de los accidentes de tráfico y puede ser igualmente aplicable,

\footnotetext{
* Autor para correspondencia.

Correo electrónico: ansantia@ucm.es (A.S. Santiago-Sáez).
}

con carácter orientativo, a otros supuestos distintos de daños indemnizables sufridos por las personas, como son los accidentes laborales y los daños sufridos por mala praxis médica (sean de responsabilidad civil o penal) ${ }^{3}$.

El propósito del nuevo baremo es conseguir que las indemnizaciones sean más individualizadas, más apropiadas a la situación de la víctima, integrando en el cálculo las circunstancias personales, familiares, laborales o profesionales de las víctimas y perjudicados, que incluyen al cónyuge, ascendientes, descendientes, hermanos y allegados ${ }^{4}$.

Para mejorar la identificación, recogida y control de los documentos necesarios o más relevantes para la elaboración de informes periciales en relación con el Real Decreto $1148 / 2015$, nuestro grupo de trabajo definió una serie de intenciones para mejorar el trabajo de los peritos y letrados implicados, que establece la lista de chequeo documental como un método eficaz, sencillo, práctico y aplicable a todo procedimiento pericial para aumentar la calidad de la recogida de datos e información necesaria, que incorpora 
Tabla 1 Requisitos documentales: datos generales, datos de la víctima lesionada y datos de la pericial

\begin{tabular}{lll}
\hline 1 Datos generales y datos de la víctima lesionada & $\begin{array}{l}\text { Cumplimiento } \\
\text { (marcar X) }\end{array}$ & $\begin{array}{l}\text { Evidencias y } \\
\text { observaciones }\end{array}$ \\
\hline
\end{tabular}

1.1. ¿Se ha rellenado correctamente el Anexo I del RD 1148/2015?

1.2. ¿Hay oferta motivada?

1.3. ¿Se cumplen las condiciones geográficas para realizar la pericial en el

IML indicado?

1.4. ¿Hay informe inicial de lesiones y de su curso evolutivo?

1.5. ¿El accidente de tráfico ocurrió a partir del 1 de enero de 2016?

1.6. ¿Se encuentra registrado el solicitante del informe?

1.7. ¿Se detalla la fecha de la solicitud?

1.8. ¿Se identifica la Entidad aseguradora?

1.9. ¿Se refiere el lugar, fecha y hora del accidente?

1.10. ¿Se reseñan el nombre y apellidos de la víctima?

1.11. ¿Se significan la edad y sexo de la víctima?

1.12. ¿Se reconocen la profesión y ocupación de la víctima?

2. Datos de la pericial

Cumplimiento

(marcar X)
Evidencias y observaciones

2.1. ¿Hay perito(s)?

2.2. ¿Existen fuentes externas del informe?

2.2.1. ¿Hay fuentes médico-asistenciales?

2.2.2. ¿Hay fuentes no asistenciales?

2.3. ¿Se describe el hecho referido (accidente)?

2.4. ¿Se detallan antecedentes patológicos relacionados con el hecho referido?

2.5. ¿Se especifica el resultado de la exploración física?

2.6. ¿Se establece $(\mathrm{n})$ diagnósticos de las lesiones?

2.7. ¿Se detalla el tratamiento y evolución clínica?

2.8. ¿Se especifica el centro asistencial y fecha de atención?

2.9. ¿Existen fuentes internas?

2.10. ¿Se detallan las consideraciones médico-legales?

la evaluación de elementos esenciales como requerimientos mínimos ${ }^{5-10}$. Porque, en definitiva, el reto del perito es dar respuesta oportuna ante los cambios propuestos por el legislador.

El objetivo de este trabajo es facilitar una herramienta que permita a los profesionales implicados (médico forense, letrado, médico valorador, tramitadores de compañías aseguradoras) adquirir una mecánica y una sistemática para recopilar, adquirir o solicitar la documentación adecuada que facilite la valoración del daño y la elaboración de informes periciales.

\section{Utilidad práctica}

El establecimiento de una lista de verificación de documentos (LVD) para facilitar la redacción de los informes periciales del demandante es una tarea compleja que requiere claridad de objetivos y perseverancia. Uno de los elementos esenciales para el éxito de una medida de este tipo es que los profesionales la consideren útil y se impliquen en el proceso de instauración, cumplimiento y posterior seguimiento de la medida para evaluar sus efectos.

El valor de la LVD como herramienta para realizar informes periciales a particulares no se puede establecer de forma aislada e independiente del conjunto de medidas transversales que supone el desarrollo e implantación de una cultura de auditorías en calidad en los profesionales médicos y médicos forenses que realizan informes periciales.

Las omisiones de información o de determinados datos relativos al paciente peritado/informado, así como los errores asociados a estos, son una causa importante de pérdida de calidad y precisión en la elaboración de informes periciales de los profesionales médicos y médicos forenses.

Entre las prácticas recomendadas para la prevención de pérdidas de calidad, destaca la LVD, un cuestionario que, sin incrementar los gastos, resulta accesible a todos los profesionales (médicos, médicos forenses y abogados), es adaptable a las necesidades de cada uno de ellos y permite distinguir el origen de los datos, o su ausencia.

Los LVD son ayudas cognitivas para la realización de determinadas actividades. Se ha demostrado su eficacia tanto para garantizar la correcta ejecución de determinadas actividades como para prevenir errores, al sistematizar las acciones y constituir un recordatorio del proceso.

Nuestro grupo de trabajo, compuesto por profesionales peritos médicos y médicos forenses, identificaron 6 objetivos o propósitos fundamentales, recogidos y extraídos del Real Decreto 1148/2015, de 18 de diciembre, por el que se regula la realización de pericias a solicitud de particulares por 
Tabla 2 Requisitos documentales: fallecimiento, lesiones temporales, secuelas y perjuicios morales

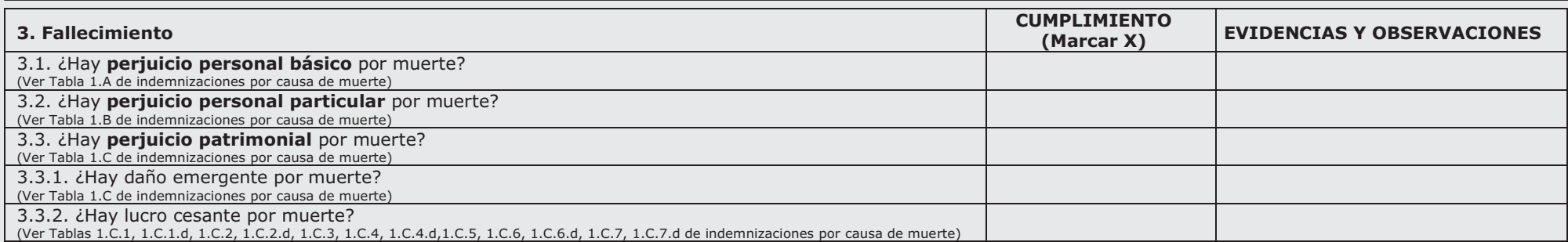

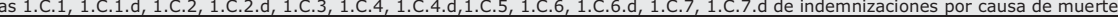

(Marcar X)

EVIDENCIAS Y OBSERVACIONES

4.1. ¿Hay perjuicio personal básico por lesiones temporales?

4.2. ¿Hay perjuicio personal particular por lesiones

temporales?

(Ver Tabla 3.B de indemnizaciones por lesiones temporales)

4.2.1. ¿Hay pérdida temporal de calidad de vida?

4.3. iHay perjuicio patrimonial por lesiones

4.3.1. ¿Hay dano emergente por lesiones temporales?

4.3.1. ¿Hay daño emergente por lesiones temporales?

4.3.1.1. ¿Hay gastos de asistencia sanitaria?

4.3.1.2. ¿Hay gastos diversos resarcibles?

4.3.2. ¿Hay lucro cesante por lesiones temporales?

5. Secuelas, daños y perjuicios morales

EVIDENCIAS Y OBSERVACIONES

5.1. ¿Hay perjuicio personal básico por secuelas?

(2. disposiciones relativas a la Tabla 2.A. Incluye Tabla 2.A.1 del baremo médico)

5.1.1. ¿Hay secuelas psicofísicas, orgánicas o sensoriales de las secuelas estéticas?

5.1.2. ¿Hay secuelas interagravatorias?

5.1.3. ¿Hay secuelas agravatorias de estado previo?

5.1.4. ¿Hay perjuicio estético?

5.2. ¿Hay perjuicio personal particular por secuelas?

(Ver disposiciones relativas a la Tabla 2.B)

5.2.1. ¿Hay daño moral complementario por perjuicio psicofísico?

(Solo si una secuela alcanza 60 puntos o las concurrentes 80 puntos)

(Ver Tabla 2.B de indemnizaciones por secuelas)

5.2.2. ¿Hay daño moral complementario por perjuicio estético?

(Solo si el perjuicio alcanza 36 puntos)

( $5.2 .3 .2 \mathrm{Hay}$ perjuizio panes por secuelas)

5.2.3. ¿Hay perjuicio particular moral por pérdida de calidad de

vida ocasionada por las secuelas?

(Ver Tabla 2.B de indemnizaciones por secuelas)

5.2.4. ¿Hay perjuicio moral por pérdida de calidad de vida de

familiares de grandes lesionados?

(Solo si el perjuicio supera los 80 puntos)

5.2.5. ¿Ha habido pérdida de feto a consecuencia de los hechos?

5.2.6. ¿Hay perjuicio excepcional?

5.3. ¿Hay perjuicio patrimonial por secuelas?

(Ver disposiciones relativas a la Tabla 2.C de indemnizaciones por secuelas)

5.3.1. ¿Hay lucro cesante?

(Ver Tablas 2.C)

5.3.2. ¿Hay daño emergente por secuelas? 
Tabla 3 Requisitos documentales: gastos previsibles de asistencia sanitaria futura y pérdida de autonomía tras la estabilización

\begin{tabular}{lll}
\hline 6. Gastos previsibles de asistencia sanitaria futura & $\begin{array}{l}\text { Cumplimiento } \\
\text { (marcar X) }\end{array}$ & $\begin{array}{l}\text { Evidencias y } \\
\text { observaciones }\end{array}$ \\
\hline
\end{tabular}

6.1. ¿Hay necesidad de rehabilitación domiciliaria y ambulatoria tras la estabilización?

6.2. ¿Hay necesidad de prótesis y ortesis tras la estabilización?

6.3. ¿Hay necesidad de ayudas técnicas para la autonomía personal tras la estabilización?

6.4. ¿Hay necesidad de adecuación de vivienda en caso de pérdida de autonomía personal tras la estabilización?

7. Pérdida de autonomía tras la estabilización

Cumplimiento

(marcar X)
Evidencias y observaciones

7.1. ¿Existe pérdida de autonomía que afecta a la movilidad?

7.2. ¿Hay necesidad de ayuda de tercera persona? (ver tabla 2.C.2 y 2.C.3)

7.3. ¿Existe incapacidad para realizar su trabajo o actividad profesional?

los Institutos de Medicina Legal y Ciencias Forenses, en las reclamaciones judiciales por hechos relativos a la circulación de vehículos a motor. A través de estos objetivos se pretende guiar a los profesionales peritos médicos y médicos forenses para evitar errores $u$ omisiones en la solicitud de información relevante para la confección de un informe pericial. Su introducción, establecimiento o promulgación puede mejorar la solicitud y consecución de toda la información relevante, que garantiza la correcta realización y verificación de un informe pericial completo y de calidad y, que previene errores al sistematizar la recogida de datos e información relevante.

Los elementos que considerar en el establecimiento del LVD para la previsión/valoración de daños personales quedan reflejados en las tablas $1-3$ y están centrados en: datos generales, datos de la víctima lesionada y datos de la pericial (tabla 1), fallecimiento, lesiones temporales, secuelas y perjuicios morales (tabla 2), gastos previsibles de asistencia sanitaria futura y pérdida de autonomía tras la estabilización (tabla 3).

Llegado el momento de elaborar la LVD, se recaba la colaboración de la Administración, de los profesionales peritos, juristas y compañías aseguradoras, en orden a facilitar el acceso a determinados aspectos documentales que motivan su petición o solicitud para realizar un informe pericial.

Tras revisar diversas fuentes documentales del Boletín Oficial del Estado, se propone reforzar una creciente cultura de auditorías en calidad en los profesionales peritos, para lograr el compromiso y la convicción de todos los profesionales implicados en la utilidad de la herramienta.

La implementación del LVD no consiste en una norma que imponga su uso. Se trata de establecer un autocontrol de calidad para recabar la mayor información posible, de manera ordenada. Es preciso crear y reforzar una creciente cultura de auditorías en calidad en los profesionales que realizan informes periciales, para lograr el compromiso y la convicción de todos los implicados en la utilidad de la herramienta.

\section{Conflicto de intereses}

Los autores declaran no tener ningún conflicto de intereses.

\section{Bibliografía}

1. Ley $35 / 2015$, de 22 de septiembre, de reforma del sistema para la valoración de los daños y perjuicios causados a las personas en accidentes de circulación. BOE núm. 228, de 23 de septiembre de 2015. Sec. I. Pág. 84473-84979.

2. Real Decreto $1148 / 2015$, de 18 de diciembre, por el que se regula la realización de pericias a solicitud de particulares por los Institutos de Medicina Legal y Ciencias Forenses, en las reclamaciones extrajudiciales por hechos relativos a la circulación de vehículos a motor. BOE núm. 303, de 19 de diciembre de 2015. Sec. I. pp. 119702-119716.

3. Borobia C. Baremos de aplicación en el ámbito laboral. En: Gil Hernández F, editor. Tratado de medicina del trabajo. 2.. ed Madrid: Elsevier; 2006. p. 147-66.

4. Rodríguez Méndez A, Santiago Sáez A, Barjau Romero D. Manual de apoyo al médico forense y valorador en el nuevo baremo de tráfico 2016. Madrid: Tráfico Ayuda; 2016. p. 126. ISBN: 978-84608-6914-6.

5. Laurance J. Peter Pronovost: Champion of checklists in critical care. Lancet. 2009 Aug 8;374:443, http: //dx.doi.org/10.1016/S0140-6736(09)61439-2

6. Pronovost P, Voh E. Safe patients, smart hospitals: How one doctor's checklist can help us change healthcare from the inside out. J Nucl Med. 2011;52:162-3, http://dx.doi.org/10.2967/jnumed.110.082537

7. Gawande A. The checklist manifiesto: How to get things right. Nueva York, NY: Metropolitan Books; 2009.

8. Leape L. The checklist conundrum. N Eng J Med. 2014;370:1063-4.

9. McLaughlin AC. What makes a good checklist? Perspectives on safety. Rockville MD: AHRQ Web M\&M.; 2010.

10. Scriven M. The logic and methodology of checklist. Western Michigan University; 2000. p. 1-11 [consultado 6 Dic 2016]. Disponible en: http://www.wmich.edu/evaluation/checklists. 